Effect of carotid and aortic baroreceptors on cardiopulmonary reflex: the role of autonomic function

T.L. Fernandes, A.C. Piratello, V. Farah, P. Fiorino, E.D. Moreira, M.C. Irigoyen and E.M. Krieger

The Brazilian Journal of Medical and Biological Research is partially financed by
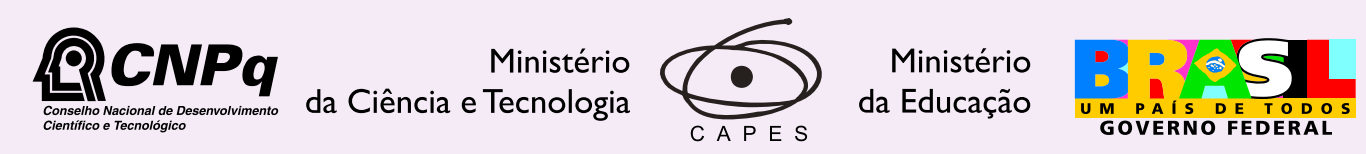

DTAPESP

Institutional Sponsors

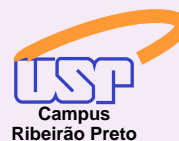

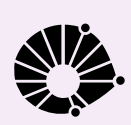

Ф SHIMADZU

GE Healthcare
Hotsite of proteomics metabolomics developped by: 


\title{
Effect of carotid and aortic baroreceptors on cardiopulmonary reflex: the role of autonomic function
}

\author{
T.L. Fernandes ${ }^{1 *}$, A.C. Piratello ${ }^{1 *}$, V. Farah ${ }^{2}$, P. Fiorino ${ }^{2}$, E.D. Moreira ${ }^{1}$, \\ M.C. Irigoyen ${ }^{1}$ and E.M. Krieger ${ }^{1}$ \\ ${ }^{1}$ Unidade de Hipertensão, Instituto do Coração, Faculdade de Medicina, \\ Universidade de São Paulo, São Paulo, SP, Brasil \\ ${ }^{2}$ Centro de Ciências Biológicas e da Saúde, \\ Universidade Presbiteriana Mackenzie, São Paulo, SP, Brasil
}

\begin{abstract}
We determined the sympathetic and parasympathetic control of heart rate (HR) and the sensitivity of the cardiopulmonary receptors after selective carotid and aortic denervation. We also investigated the participation of the autonomic nervous system in the Bezold-Jarish reflex after selective removal of aortic and carotid baroreceptors. Male Wistar rats (220-270 g) were divided into three groups: control ( $C G, N=8)$, aortic denervation ( $A G, N=5)$ and carotid denervation $(C A G, N=9)$. $A G$ animals presented increased arterial pressure (12\%) and HR (11\%) compared with CG, while CAG animals presented a reduction in arterial pressure $(16 \%)$ and unchanged HR compared with CG. The sequential blockade of autonomic effects by atropine and propranolol indicated a reduction in vagal function in CAG (a 50 and $62 \%$ reduction in vagal effect and tonus, respectively) while AG showed an increase of more than $100 \%$ in sympathetic control of HR. The Bezold-Jarish reflex was evaluated using serotonin, which induced increased bradycardia and hypotension in AG and CAG, suggesting that the sensitivity of the cardiopulmonary reflex is augmented after selective denervation. Atropine administration abolished the bradycardic responses induced by serotonin in all groups; however, the hypotensive response was still increased in AG. Although the responses after atropine were lower than the responses before the drug, indicating a reduction in vagal outflow after selective denervation, our data suggest that both denervation procedures are associated with an increase in sympathetic modulation of the vessels, indicating that the sensitivity of the cardiopulmonary receptors was modulated by baroreceptor fibers.
\end{abstract}

Key words: Carotid denervation; Aortic denervation; Bezold-Jarish reflex

\section{Introduction}

The physiological role of arterial baroreceptors in the maintenance of circulatory homeostasis has been well established. The surgical deafferentation of these baroreceptors as described by Krieger (1) leads to a marked increase in arterial pressure variability (APV), providing an experimental model of the complete absence of baroreceptor function, since the arterial baroreceptor reflex plays an important role in preventing short-term wide fluctuations (2-4). However, there is a different degree of baroreflex impairment in the presence of cardiovascular diseases such as hypertension, myocardial infarction and heart failure, causing a reduction of baroreflex sensitivity associated with increased APV $(5,6)$. Indeed, the reduction of baroreflex sensitivity has been demonstrated to be a significant predictor of cardiac mortality $(7,8)$.

The reflex control of the cardiovascular system also depends on the activation of cardiopulmonary receptors (9). The Bezold-Jarish reflex is one of the cardiac reflexes that contribute to cardiovascular control. This reflex is characterized by an increase in parasympathetic efferent activity associated with inhibition of sympathetic efferent activity resulting in hypotension and bradycardia. The chemical stimulation of cardiopulmonary receptors with serotonin is an effective method for inducing the Bezold-Jarish reflex in animals $(10,11)$. The sensitivity of the Bezold-Jarish reflex evaluated with serotonin was increased after sinoaortic

Correspondence: M.C. Irigoyen, Unidade de Hipertensão, INCOR, FM, USP, Av. Dr. Enéas de Carvalho Aguiar, 44, 05403-000 São Paulo, SP, Brasil. Fax: +55-11-3069-5048. E-mail: hipirigoyen@incor.usp.br

*These authors contributed equally to this study.

Received January 5, 2010. Accepted May 24, 2010. Available online July 9, 2010. Published July 9, 2010. 
denervation (SAD), suggesting that there is an important functional role in the maintenance of cardiovascular homeostasis by the cardiopulmonary receptors in the absence of the baroreceptors (12).

The cardiovascular effects observed in complete (nonselective) SAD depend on the net effect of eliminating excitatory and inhibitory influences (chemoreceptor and baroreceptor elimination, respectively). However, there is no information about the separate effects of each of the two sets of baroreceptors.

Thus, in the present study, we tested the hypothesis that only carotid or aortic denervation can selectively modulate the autonomic control of the circulation and the sensitivity of the cardiopulmonary receptors. Moreover, since there is some evidence that alterations in the characteristics of baroreflex sensitivity reflect alterations in autonomic control of the cardiovascular system (6), we also determined the participation of the autonomic nervous system in the Bezold-Jarish reflex after selective removal of aortic and carotid baroreceptors.

\section{Material and Methods}

\section{Animals}

The experiments were performed on male Wistar rats weighing 220-270 g, housed in cages with free access to water and food, and maintained in a room with a constant temperature $\left(23^{\circ} \mathrm{C}\right)$ on a 12-h light/dark cycle. All surgical procedures and protocols used were in accordance with the Guidelines for Ethical Care of Experimental Animals and were approved by the Institutional Animals Care and Use Committee. The rats were randomly divided into three groups: carotid denervation ( $C A G, N=9$ ), aortic denervation ( $A G, N=5)$, and control ( $C G, N=8)$.

For the surgical procedures the animals were anesthetized intraperitoneally (ip) with a mixture of $80 \mathrm{mg} / \mathrm{kg}$ ketamine (Parke-Davis, Brazil) and $12 \mathrm{mg} / \mathrm{kg}$ xylazine (Bayer, Brazil). The control group was submitted to sham operation.

\section{Baroreceptor denervation}

The SAD method described by Krieger (1) was used, ex- cept that the aortic fibers of the baroreceptors were preserved in the carotid denervation. A midline neck incision was made, and sternocleidomastoid muscles were reflected laterally, exposing the neurovascular sheath. The carotid bifurcation was exposed, the carotid fibers were interrupted bilaterally and the carotid body was resected.

For aortic denervation, a midline neck incision was made and the aortic fibers of the baroreceptors that travel along the sympathetic trunk or as isolated nerves were sectioned, keeping the carotid fibers and carotid body intact. Another contingent of baroreceptor aortic fibers located along the inferior laryngeal nerve was interrupted when sectioning the superior laryngeal nerve.

\section{Catheterization and arterial pressure recording}

One day after carotid and aortic denervation, arterial and venous catheters were placed in the right femoral artery and vein for direct measurements of arterial pressure (AP) and for drug administration. The catheters were exteriorized through the back of the neck.

The AP signals were recorded continuously in conscious, freely moving rats. The arterial catheter was connected to a transducer (Blood Pressure XDCR, Kent ${ }^{\circledR}$ Scientific, USA), and AP signals were recorded over a 20 -min period by a microcomputer equipped with an analogy-to-digital converter board (CODAS, $2000 \mathrm{~Hz}$ sampling frequency, Dataq Instruments, Inc., USA). The recorded data were analyzed on a beat-to-beat basis to quantify changes in mean arterial pressure (MAP) and heart rate (HR).

$A P$ and HR variability was evaluated on the basis of the standard deviation.

\section{Gasometry}

One day after carotid and aortic denervation, a small amount of blood $(0.2 \mathrm{~mL})$ was collected from the femoral artery and analyzed with an ABL-5 instrument (Radiometer, Copenhagen, Denmark) to determine $\mathrm{pCO}_{2}$ and $\mathrm{pO}_{2}$.

\section{Bezold-Jarish reflex test}

The responses to stimulation of chemosensitive cardiopulmonary receptors (Bezold-Jarish reflex) were determinate in conscious rats. After recording 20 min of resting AP

Table 1. Mean arterial pressure (MAP), arterial pressure variability (APV), heart rate $(\mathrm{HR})$, heart rate variability ( $\mathrm{HRV})$, and $\mathrm{pCO}_{2}$ and $\mathrm{pO}_{2}$ concentrations in the control group (CG), carotid group (CAG) and aortic group (AG).

\begin{tabular}{lcccccc}
\hline Groups & MAP & APV & HR & HRV & $\mathrm{pCO}_{2}$ & $\mathrm{pO}_{2}$ \\
\hline $\mathrm{CG}(\mathrm{N}=8)$ & $110 \pm 3.4$ & $5.2 \pm 0.4$ & $364 \pm 5.1$ & $20 \pm 2.8$ & $36 \pm 0.7$ & $80 \pm 2.1$ \\
$\mathrm{CAG}(\mathrm{N}=9)$ & $92 \pm 7^{\#}$ & $10.5 \pm 1.3^{\#}$ & $351 \pm 6.2$ & $20 \pm 3.6$ & $48 \pm 1.4^{\#}$ & $58 \pm 2.2^{\#}$ \\
$\mathrm{AG}(\mathrm{N}=5)$ & $122 \pm 3.3^{*}$ & $10.4 \pm 0.9^{*}$ & $407 \pm 8.9^{*}$ & $26 \pm 3.7$ & $35 \pm 0.8$ & $78 \pm 1.7$ \\
\hline
\end{tabular}

\#P $\leq 0.001$ for the CAG group versus the CG group; * $\mathrm{P} \leq 0.001$ for the AG group versus the CG group (one-way ANOVA). 
and $H R$, the animals were successively injected with 2, 4, and $8 \mu \mathrm{g} / \mathrm{kg}$ serotonin (5-HT; Sigma, USA) while MAP and HR were recorded. For data analysis, control and peak changes of MAP and HR after each dose were analyzed with a microcomputer (IBM-AT/CODAS, Brazil). Injections were not repeated until the recorded parameters had returned to pre-injection levels. The tests were repeated before and after pharmacological blockade of the parasympathetic nervous system.

\section{Pharmacological blockade}

Pharmacological blockade was performed in the same animals on 2 consecutive days.

On the 1 st day of the study, immediately after the resting $\mathrm{HR}$ was recorded, $4 \mathrm{mg} / \mathrm{kg}$ atropine (Sigma), a cholinergic receptor antagonist, was injected intravenously (iv). After atropine injection, AP and HR were recorded for 15 min to permit the antagonists to exert their full effects and the Bezold-Jarish test was then repeated. Propranolol (4 mg/ kg; Sigma), a beta-adrenergic receptor antagonist, was administered iv after the Bezold-Jarish test, and the AP and $\mathrm{HR}$ responses were recorded for $5 \mathrm{~min}$. The intrinsic heart rate (IHR) was measured after simultaneous blockade with propranolol and atropine. On the 2 nd day of the study, propranolol was administered first to obtain the inverse sequence of blockade.

The vagal effect was the difference between the maximum HR after atropine injection and the control HR, on the 1st day. The sympathetic effect was the difference between the control HR and minimum HR after propranolol injection on the 2 nd day. The vagal tone was calculated as the difference between the IHR and the HR after propranolol injection on the 2 nd day. The sympathetic tone was the difference between the HR after atropine injection and the $\mathrm{IHR}$, on the 1st day.

Statistical analysis for the comparison of MAP, APV, $\mathrm{HR}, \mathrm{HR}$ variability, $\mathrm{pCO}_{2}, \mathrm{pO}_{2}, \mathrm{IHR}$, vagal, and sympathic

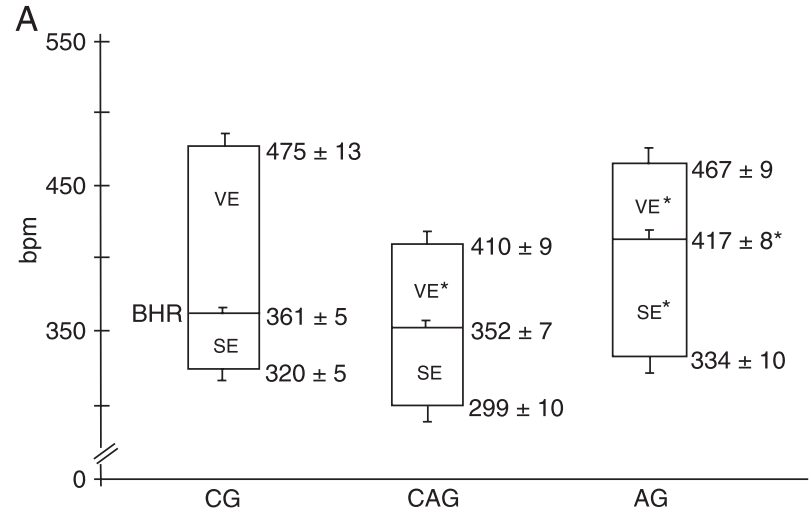

effects was performed by one-way ANOVA followed by the Newman-Keuls test. The responses of the reflex after successive injections of serotonin were also compared by two-way ANOVA followed by the Newman-Keuls test. The results are reported as means \pm SEM.

\section{Results}

Aortic denervation increased MAP while carotid denervation decreased it. The APV of CAG and AG was increased compared with $C G(P=0.001$ and $P=0.0005$, respectively). The HR of the AG was increased when compared with $C G$ $(P=0.001)$. CAG rats presented a reduction of $\mathrm{pO}_{2}(P=$ $0.0001)$ accompanied by an increase of $\mathrm{pCO}_{2}(\mathrm{P}=0.0001)$ compared with CG animals (Table 1).

The IHR obtained after pharmacological blockage was lower in CAG than in CG (344 \pm 8.0 vs $401 \pm 6.9$ bpm; P $=0.0003)$, and the vagal effect was decreased in AG (P $=0.009)$ and CAG $(P=0.03)$ compared with $C G(A G=$ $50 \pm 11.2, \mathrm{CAG}=58 \pm 8.3$ vs $\mathrm{CG}=114 \pm 13 \mathrm{bpm})$. The sympathetic effect was higher in AG compared with CG (83 \pm 2.1 vs $41 \pm 5$ bpm; $P=0.0002$; Figure $1 \mathrm{~A}$ ). Vagal and sympathetic tonus was lower in CAG when compared with CG $(P=0.04)$, as shown in Figure 1B.

As expected, serotonin induced significant bradycardia and hypotension. The bradycardic response was higher in AG than CG (275 \pm 15 vs $163 \pm 17$ bpm, respectively; $P=$ 0.001 ; Figure 2B).

The hypotensive response to serotonin (decreased MAP) was increased in AG $(P=0.0001)$ and CAG $(P=$ $0.0008)$ compared with $C G(A G=46 \pm 5$ and $C A G=36 \pm$ 4 vs CG = $19 \pm 2 \mathrm{mmHg}$, respectively; Figure $2 \mathrm{~A}$ ).

The hypotensive response after atropine administration was higher in $A G(P=0.0001)$ than in $C G(A G=11 \pm 2$ vs $C G=4.5 \pm 0.7 \mathrm{mmHg}$ ) and the bradycardic response did not differ between groups (Figure 2A,B).

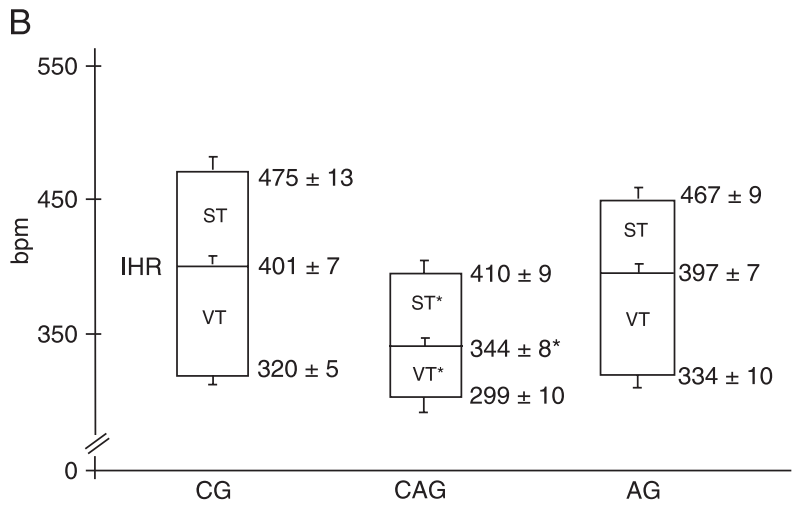

Figure 1. $A$, Vagal (VE) and sympathetic (SE) effect and $B$, vagal (VT) and sympathetic (ST) tonus of the control group (CG), carotid group (CAG) and aortic group (AG). IHR = intrinsic heart rate; BHR = basal heart rate. ${ }^{*} \mathrm{P}<0.05$ versus CG (one-way ANOVA). 

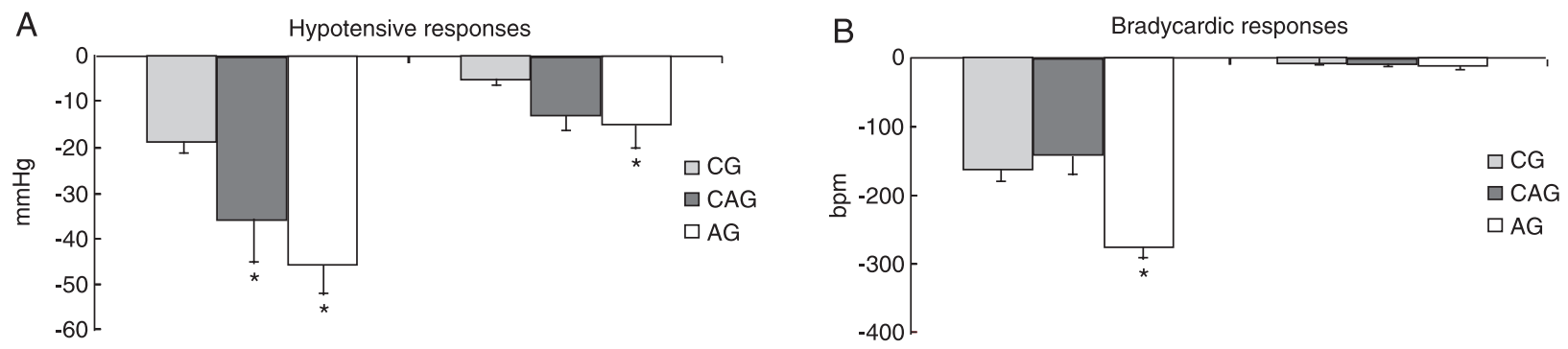

Figure 2. $A$, Mean hypotensive response obtained with all doses of serotonin before and after atropine administration; $B$, mean bradycardic response obtained with all doses of serotonin before and after atropine administration for the control group (CG), carotid group (CAG) and aortic group (AG). *P $<0.05$ versus CG (two-way ANOVA).

\section{Discussion}

Clinical and experimental studies have demonstrated the role of cardiopulmonary receptors in normal and pathophysiological conditions, showing the importance of these receptors in cardiovascular control $(9,11,13-16)$. In fact, the Bezold-Jarish reflex obtained by serotonin administration has been evaluated in several experimental studies and was found to be impaired in spontaneously hypertensive rats (17) and in renal hypertensive rats (18). In contrast, this reflex is enhanced in hypertensive rats by inhibition of nitric oxide synthase (19) and after acute myocardial infarction (16) and is still preserved in diabetic rats (11). These studies have confirmed the idea that the neural reflex control of circulation depends not only on baroreflex input but also on cardiopulmonary reflexes $(9,13,14)$.

The interplay between arterial and cardiopulmonary baroreflexes has been demonstrated in several experimental studies $(10,12,17,20)$. Tonic inhibition of both carotid chemoreflex and arterial baroreflex is produced by cardiopulmonary vagal afferent activity (21). However, the role of the cardiopulmonary reflex in the control of the circulation in the absence of baroreflex control after SAD is not completely understood. In dogs, it was suggested that cardiopulmonary afferents could be counteracting the increase in sympathetic activity after removal of arterial baroreceptors $(22,23)$. In addition, Chianca Júnior and Machado (12) showed a significant increase in the sensitivity of the Bezold-Jarish reflex in both acute and chronic sinoaortic denervated rats. However, there is no information about the separate participation of the aortic baroreceptors or of the carotid baroreceptors in Bezold-Jarish sensitivity. Thus, in the present study, we evaluated the sensitivity of the Bezold-Jarish reflex after acute $(24 \mathrm{~h})$ selective aortic or carotid denervation.

In the present study, we have confirmed that the animals submitted to aortic denervation had increased MAP and HR while animals submitted to carotid denervation had a reduction in MAP with no changes in HR, as previously demonstrated (24-30). Moreover, APV was higher in both groups of animals submitted to denervation when compared with intact controls. Studies have shown that sinoaortic denervated rats had hypertension, tachycardia, and increased APV in the acute phase, whereas in the chronic phase HR and AP returned to normal and APV remained increased (4). Regarding the arterial blood gases, CAG animals showed significantly reduced arterial $\mathrm{pO}_{2}$ and significantly increased $\mathrm{pCO}_{2}$. Huckstorf et al. (31) and Franchini and Krieger (30) obtained similar data when comparing carotid body-denervated and sham-operated control rats.

The stimulation of the cardiopulmonary receptors by the injection of serotonin usually induces bradycardic and hypotensive responses (Bezold-Jarish effect) (10-12). In the present experiment, these responses were increased in $A G$ compared with $C G$, suggesting that the sensitivity of the cardiopulmonary reflex is augmented in AG. Parasympathetic blockade with atropine caused a marked reduction in the bradycardic and hypotensive response induced by serotonin in all groups, confirming data from Chianca Júnior and Machado (32), which showed that the hypotensive response induced by the Bezold-Jarish reflex was due to both sympathetic withdrawal and decreased cardiac output produced by vagal-induced bradycardia. However, the hypotensive response was still augmented in AG when compared with CG. The higher hypotensive response in $A G$ after atropine blockade suggests an intense withdrawal of peripheral sympathetic activity in this group after serotonin stimulation. Indeed, this finding is consistent with studies that demonstrated an increase in sympathetic activity in animals with aortic denervation (33), as well as a reduced baroreceptor function of carotid baroreceptors, as previously described in rats (34).

Our data indicate that atropine administration abolished serotonin-induced bradycardia responses while hypotensive responses were maintained. Although the responses after atropine were lower than the responses before administration of the drug, the blockade indicated that both denervation procedures are associated with an increase in sympathetic modulation of the vessels. Indeed, after atropine blockade all groups showed reduced hypotensive responses, although the AG response was more marked than that of the other groups. This finding suggests an overactivity of 
the sympathetic system in this group. On the other hand, hypotension in CG and CAG animals was predominantly due to parasympathetic influence on the heart.

The chemoreflex induced by activation from peripheral chemoreceptors located in the aortic and carotid bodies has been extensively studied as one of the neural controls of blood pressure regulation (35-37). These chemosensitive cells are excited by decreases in $\mathrm{pO}_{2}$ or increases in $\mathrm{pCO}_{2}$ or $\mathrm{pH}$ that will stimulate the terminal innervations of the carotid sinus nerve (38). Our data showed a marked reduction in IHR associated with a decrease in vagal function after selective carotid denervation. These results could be explained at least in part by the hypoxia observed after carotid denervation, since these animals showed a decrease in $\mathrm{pO}_{2}$ and $\mathrm{pH}$ simultaneously with an increase in $\mathrm{pCO}_{2}$.

The relationship between hypoxia and the autonomic nervous system has been demonstrated in several animal studies, which have evaluated the cardiovascular autonomic

\section{References}

1. Krieger EM. Neurogenic hypertension in the rat. Circ Res 1964; 15: 511-521.

2. Cowley AW Jr, Liard JF, Guyton AC. Role of baroreceptor reflex in daily control of arterial blood pressure and other variables in dogs. Circ Res 1973; 32: 564-576.

3. Jacob HJ, Brown DM, Bunker RK, Daly MJ, Dzau VJ, Goodman A, et al. A genetic linkage map of the laboratory rat, Rattus norvegicus. Nat Genet 1995; 9: 63-69.

4. Soares PP, Porto CS, Abdalla FM, De La Fuente RN, Moreira $E D$, Krieger EM, et al. Effects of rat sinoaortic denervation on the vagal responsiveness and expression of muscarinic acetylcholine receptors. J Cardiovasc Pharmacol 2006; 47: 331-336.

5. Floras JS, Jones JV, Hassan MO, Sleight P. Effects of acute and chronic beta-adrenoceptor blockade on baroreflex sensitivity in humans. J Auton Nerv Syst 1988; 25: 87-94.

6. Eckberg DL, Sleight P. Human baroreflex in health and disease. Oxford: Clarendon Press; 1992.

7. La Rovere MT, Bigger JT Jr, Marcus FI, Mortara A, Schwartz PJ. Baroreflex sensitivity and heart-rate variability in prediction of total cardiac mortality after myocardial infarction. ATRAMI (Autonomic Tone and Reflexes After Myocardial Infarction) Investigators. Lancet 1998; 351: 478-484.

8. Schwartz PJ, La Rovere MT. ATRAMI: a mark in the quest for the prognostic value of autonomic markers. Autonomic Tone and Reflexes After Myocardial Infarction. Eur Heart $J$ 1998; 19: 1593-1595.

9. Zanchetti A, Mancia G. Cardiovascular reflexes and hypertension. Hypertension 1991; 18: III-13-III-21.

10. Thoren P. Role of cardiac vagal $\mathrm{C}$-fibers in cardiovascular control. Rev Physiol Biochem Pharmacol 1979; 86: 1-94.

11. Oliveira VL, Moreira ED, Farah VD, Consolim-Colombo F, Krieger EM, Irigoyen MC. Cardiopulmonary reflex impairment in experimental diabetes in rats. Hypertension 1999; 34: 813-817.

12. Chianca Júnior DA, Machado BH. The sensitivity of the Bezold-Jarisch reflex is increased in rats with sinoaortic responses to hypoxia. In fact, recently, Sugimura et al. (39), using spectral analysis methods, have demonstrated that acute progressive hypoxia inhibits cardiac parasympathetic activity in hypertensive rats. Therefore, a possible mechanism for the alterations observed in cardiac parasympathetic control in CAG could be related to hypoxia itself (40).

In conclusion, our data showed that both carotid and aortic baroreceptors selectively modulated the sensitivity of the cardiopulmonary receptors. This modulation was associated with the effects of chemo- and baroreceptor fiber activities coming from the carotid region or with tonic inhibition of sympathetic activity depending on aortic nerve input to the central nervous system.

\section{Acknowledgments}

Research supported by FAPESP (\#99/09959-0). deafferentation. Braz J Med Biol Res 1994; 27: 775-781.

13. Mark AL. The Bezold-Jarisch reflex revisited: clinical implications of inhibitory reflexes originating in the heart. J Am Coll Cardiol 1983; 1: 90-102.

14. Mark AL, Kerber RE. Augmentation of cardiopulmonary baroreflex control of forearm vascular resistance in borderline hypertension. Hypertension 1982; 4: 39-46.

15. Meyrelles SS, Cabral AM, Vasquez EC. Impairment of the Bezold-Jarisch reflex in conscious rats with myocardial hypertrophy. Braz J Med Biol Res 1994; 27: 1065-1069.

16. Lacerda JE, Consolim-Colombo FM, Moreira ED, Ida F, Silva GJ, Irigoyen MC, et al. Influence of cardiopulmonary reflex on the sympathetic activity during myocardial infarction. Auton Neurosci 2007; 133: 128-135.

17. Verberne AJ, Guyenet PG. Medullary pathway of the BezoldJarisch reflex in the rat. Am J Physiol 1992; 263: R1195R1202.

18. Thames MD, Johnson LN. Impaired cardiopulmonary baroreflex control of renal nerves in renal hypertension. Circ Res 1985; 57: 741-747.

19. Araujo MT, Cabral AM, Vasquez EC. Exaggerated BezoldJarisch reflex in the hypertension induced by inhibition of nitric oxide synthesis. Braz J Med Biol Res 1995; 28: 10091012.

20. Bishop VS, Hasser EM. Arterial and cardiopulmonary reflexes in the regulation of the neurohumoral drive to the circulation. Fed Proc 1985; 44: 2377-2381.

21. Koike H, Mark AL, Heistad DD, Schmid PG. Influence of cardiopulmonary vagal afferent activity on carotid chemoreceptor and baroreceptor reflexes in the dog. Circ Res 1975; 37: 422-429.

22. Persson P, Ehmke H, Kirchheim H, Seller H. Effect of sinoaortic denervation in comparison to cardiopulmonary deafferentiation on long-term blood pressure in conscious dogs. Pflugers Arch 1988; 411: 160-166.

23. Persson PB, Ehmke H, Kirchheim HR. Blood pressure control in arterial- and cardiopulmonary receptor denervated 
dogs. Acta Physiol Scand 1991; 142: 221-228.

24. Bedran de Castro MT, Moreira ED, Krieger EM. Reflex and central components of carotid occlusion in conscious rats: effect of lesion of the medial forebrain bundle. Hypertension 1986; 8: 47-51.

25. Krieger EM. The acute phase of neurogenic hypertension in the rat. Experientia 1970; 26: 628-629.

26. Fink GD, Bryan WJ, Mann M, Osborn J, Werber A. Continuous blood pressure measurement in rats with aortic baroreceptor deafferentation. Am J Physiol 1981; 241: $\mathrm{H} 268-\mathrm{H} 272$.

27. Patel KP, Ciriello J, Kline RL. Noradrenergic mechanisms in brain and peripheral organs after aortic nerve transection. Am J Physiol 1981; 240: H481-H486.

28. Zhang TX, Ciriello J. Effect of paraventricular nucleus lesions on arterial pressure and heart rate after aortic baroreceptor denervation in the rat. Brain Res 1985; 341: 101-109.

29. Zhang TX, Ciriello J. Kainic acid lesions of paraventricular nucleus neurons reverse the elevated arterial pressure after aortic baroreceptor denervation in the rat. Brain Res 1985; 358: 334-338.

30. Franchini KG, Krieger EM. Carotid chemoreceptors influence arterial pressure in intact and aortic-denervated rats. Am J Physiol 1992; 262: R677-R683.

31. Huckstorf C, Behm R, Habeck JO, Ruckborn K, Franz U. Blood pressure, heart rate and arterial blood gas reactions to acute hypoxia in carotid body denervated spontaneously hypertensive rats. Biomed Biochim Acta 1987; 46: 925931.

32. Chianca DA Jr, Machado BH. Microinjection of NMDA antagonist into the NTS of conscious rats blocks the Bezold-
Jarisch reflex. Brain Res 1996; 718: 185-188.

33. Irigoyen MC, Moreira ED, Ida F, Pires M, Cestari IA, Krieger EM. Changes of renal sympathetic activity in acute and chronic conscious sinoaortic denervated rats. Hypertension 1995; 26: 1111-1116.

34. Franchini KG, Krieger EM. Neurogenic hypertension in the rat. In: Ganten D, de Jong W (Editors), Handbook of hypertension: experimental and genetic models of hypertension. Amsterdam: Elsevier Science Publishers B.V.; 1994. p 482500.

35. Marshall JM. Analysis of cardiovascular responses evoked following changes in peripheral chemoreceptor activity in the rat. J Physiol 1987; 394: 393-414.

36. Hayward LF, Felder RB. Peripheral chemoreceptor inputs to the parabrachial nucleus of the rat. Am J Physiol 1995; 268: R707-R714.

37. Vardhan A, Kachroo A, Sapru HN. Excitatory amino acid receptors in the nucleus tractus solitarius mediate the responses to the stimulation of cardio-pulmonary vagal afferent C fiber endings. Brain Res 1993; 618: 23-31.

38. Gonzalez C, Almaraz L, Obeso A, Rigual R. Oxygen and acid chemoreception in the carotid body chemoreceptors. Trends Neurosci 1992; 15: 146-153.

39. Sugimura M, Hirose $Y$, Hanamoto $H$, Okada K, Boku A, Morimoto $\mathrm{Y}$, et al. Influence of acute progressive hypoxia on cardiovascular variability in conscious spontaneously hypertensive rats. Auton Neurosci 2008; 141: 94-103.

40. Ziegler MG, Nelesen RA, Mills PJ, Ancoli-Israel S, Clausen $\mathrm{JL}$, Watkins L, et al. The effect of hypoxia on baroreflexes and pressor sensitivity in sleep apnea and hypertension. Sleep 1995; 18: 859-865. 